\title{
ERRATUM
}

\section{Erratum to: The Role of Weather in Meningitis Outbreaks in Navrongo, Ghana: A Generalized Additive Modeling Approach}

\author{
Vanja Dukić, Mary Hayden, Abudulai Adams Forgor, Tom Hopson, \\ Patricia Akweongo, Abraham Hodgson, Andrew Monaghan, \\ Christine Wiedinmyer, Tom Yoksas, Madeleine C. THOMSON, \\ Sylwia TRZASKA, and Raj PANDYA
}

\section{Erratum to: J. Agric. Biol. Environ. Stat.}

DOI 10.1007/s13253-012-0095-9

The author affiliations appeared incorrectly on the original publication of this article. The correct affiliations appear below.

[Published Online August 2012.]

\begin{abstract}
Vanja Dukić $(\varangle)$ is Associate Professor, Department of Applied Mathematics, University of Colorado, Boulder, CO, USA (E-mail: Vanja.Dukic@Colorado.edu). Mary Hayden, Tom Hopson, Andrew Monaghan, and Christine Wiedinmyer are Scientists, National Center of Atmospheric Research, Boulder, CO, USA. Abudulai Adams Forgor is Medical Superintendent, War Memorial Hospital, Ghana Health Service, Navrongo, Ghana. Patricia Akweongo is Senior Lecturer, Department of Health Policy, Planning \& Management, School of Public Health, University of Ghana, Legon, Accra, Ghana. Abraham Hodgson is Director of Research and Development Division, Ghana Health Service, Navrongo, Ghana. Tom Yoksas is Head of User Support at Unidata Program Center and Raj Pandya is Director of Spark UCAR Science Education, University Corporation for Atmospheric Research, Boulder, CO, USA. Madeleine C. Thomson is Director of Impacts Research, Co-Director of Africa Program and Senior Research Scientist, International Research Institute for Climate and Society, and Mailman School of Public Health, Columbia University, New York City, NY, USA. Sylwia Trzaska is Associate Research Scientist at the Center for International Earth Science Information Network, Columbia University, New York City, NY, USA.

The online version of the original article can be found under doi:10.1007/s13253-012-0095-9.
\end{abstract}

(C) 2012 International Biometric Society

Journal of Agricultural, Biological, and Environmental Statistics, Volume 17, Number 3, Page 526 DOI: $10.1007 /$ s13253-012-0109-7 